\title{
Continuity and change in dominance relations among female baboons
}

\author{
AMY SAMUELS*, JOAN B. SILK† \& JEANNE ALTMANN\$ \\ * $\ddagger$ Department of Conservation Biology, Chicago Zoological Society, Brookfield Zoo, Brookfield, IL \\ 60513, U.S.A. \\ *+†Department of Biology, The University of Chicago, Chicago, IL 60637, U.S.A. \\ $*+\ldots$ Institute of Primate Research, National Museums of Kenya, Kenya
}

\begin{abstract}
Female baboons, Papio cynocephalus, in Amboseli National Park establish linear dominance hierarchies in which maternal kin usually occupy adjacent ranks. Previous work had shown that few changes in the relative rank order of matrilines had occurred between 1971 and 1981 (Hausfater et al. 1982). During a 9-month period beginning in December 1982, the rate and magnitude of changes in matrilineal rank order accelerated. Major changes in the relative ranks of members of a few matrilines resulted in changes in the absolute ranks of females of all but one matriline. However, the ordering between many pairs of matrilines did not change and the genealogical structure of dominance relations was generally maintained. This brief period of rapid change was succeeded by a period of slow change and relative stability in dominance relations, lasting at least 27 months. Data from the 15 -year period suggest that the rates of change in female dominance relations are variable: long periods of stability are sometimes punctuated by short periods of instability and change. No single explanation accounted for this variability.
\end{abstract}

Longitudinal studies of dyadic dominance relations among adult females of several cercopithecine primate species have demonstrated that females establish linear dominance hierarchies that are stable for many years and in which daughters usually occupy ranks adjacent to those of their mothers (e.g. Cercopithecus aethiops, Cheney et al. 1981; Macaca arctoides, Estrada 1978; M. fascicularis, Angst 1975; M. fuscata, Koyama 1967; M. mulatta, Sade 1972; M. nemestrina, Bernstein 1969; M. radiata, Silk et al. 1981; Papio anubis, Scott 1984; P. cynocephalus, Hausfater et al. 1982). During the first 10 years in which a group of freeranging yellow baboons, $P$. cynocephalus, in Amboseli National Park was studied (1971-1981), few changes in dominance order were observed, other than those that resulted from deaths or maturations of females. At the end of this decade, nearly all of the adult females in the group occupied ranks that conformed to the positions occupied by members of their matrilines a decade earlier (Haus-

\footnotetext{
$\uparrow$ Present address: California Primate Research Center, University of California, Davis, CA 95616 and Department of Anthropology, University of California, Los Angeles CA 90024, U.S.A.
}

fater et al. 1982). Here, we describe several major changes in dominance rank that occurred in the same group during a 9-month period following this long period of stability. This brief period of rapid change was then succeeded by a period of slow change and relative stability in dominance relations, lasting at least 27 months.

The consistency of female dominance ranks over time is an important factor in evaluating the adaptive significance of female dominance rank in cercopithecine primates (e.g. Gouzoules et al. 1982; Hausfater et al. 1982; Silk \& Boyd 1983). High ranking females typically obtain priority of access to scarce resources and often reproduce more successfully than do lower ranking females (reviewed by Fedigan 1983; Silk 1987). If dominance rank remains stable over the course of a female's lifetime, such advantages could substantially increase her lifetime fitness. Conversely, if rank fluctuates over shorter time intervals, advantages gained while the female is high ranking could be at least partially offset by disadvantages incurred while she is low ranking. It is, therefore. important to know the rate and magnitude of rank changes among females, and to identify the factors that contribute to changes, or conversely, to maintenance of dominance rank. 


\section{SUBJECTS AND METHODS}

\section{Study Group and Site}

Observations of the free-ranging baboon population in Amboseli National Park, Kenya, were initiated in 1963 by S. and J. Altmann (Altmann \& Altmann 1970). Since 1971, the members of Alto's Group, subjects of this report, have been habituated to the presence of human observers, individually identified, and observed regularly. (See Hausfater 1975; Altmann et al. 1977, 1981; Altmann 1980; and Hausfater et al. 1982 for more complete descriptions of the study population, site and long-term data collection procedures.)

In late 1972, Alto's Group fused with High Tail's Group to form a single group (Altmann et al. 1977; Altmann 1980). The members of the resultant group, called Alto's Group, foraged, travelled and acted as an integrated unit. However, by the late 1970s social bonds still remained strongest among the members of matrilines that belonged to the same original group (Altmann 1980). Moreover, until the period described in this report, members of all but two of the matrilines that belonged to Alto's Group before the two groups fused dominated members of matrilines originally from High Tail's Group.

The events that we describe here occurred between December 1982 and December 1985, more than a decade after the fusion of Alto's and High Tail's groups. On 1 December 1982, Alto's Group consisted of eight adult males, three subadult males, 19 adult females, six juvenile males, three juvenile females, four infant males and nine infant females (age-sex categories defined as in Altmann et al. 1981). On 30 November 1985, at the end of the period under consideration, there were 14 adult males, three subadult males, 17 adult females, 10 juvenile males, 15 juvenile females, four infant males and six infant females in Alto's Group. Changes in the number of adult females in the group resulted from the maturation of three adolescent females (AL-g2, PR-d2 and SC-d3; naming conventions described below), and the deaths of five adult females (PR, SC, AL-d1, PR-d1 and SL).

\section{Analysis of Dominance Relationships}

Observations of dyadic agonistic interactions with clearly decided outcomes were used to determine the dominance relations among adult females. Data on agonistic interactions were collected on 494 days during approximately $3900 \mathrm{~h}$ of observations. During this period more than 5800 'decided' agonistic interactions among adult females were observed. The methods and terminology used to assess and describe dominance relations among the Amboseli baboons are presented in detail in Hausfater (1975) and Walters (1980). Briefly, decided agonistic bouts are those in which one individual, the 'loser', performs submissive behaviour (e.g. grimace, tail up, cower) and no aggressive behaviour (e.g. bite, hit, lunge) in response to aggressive or neutral behaviour by the 'winner'. The frequencies of the bout outcomes are entered into a square matrix, in which females are listed in descending rank order so as to minimize the number of entries below the diagonal (reversals).

Changes in dyadic dominance relations were assessed in the following way. Suppose that, initially, female A consistently lost to female B. If A was the subsequent winner against $B$ during two different months, and $B$ did not defeat $A$ during that period, A was considered to be dominant to B. The change in rank was assumed to have occurred during the month in which A was first observed to defeat B. Periods during which both $\mathrm{A}$ and $\mathrm{B}$ defeated each other were considered to be periods of inconsistent dominance (Hausfater 1975), and no changes in rank were assigned. By these criteria, all reversals in rank described in this report were permanent and long-lasting.

\section{Conventions for Naming Animals}

To facilitate comparisons with the results described by Hausfater et al. (1982), we use the same conventions for naming baboons. The oldest known female members of each family, the 'matriarchs', are named with codes that consist of the first two letters of their names (e.g. SC for Scar). Their descendants are identified with the same uppercase code, plus a lowercase letter that indicates their relationship to the matriarch ( $d=$ daughter, $g=$ granddaughter , and a single digit number that indicates their birth order. For example, AL- $\mathrm{d} \mathbf{l}$ is the oldest surviving daughter of female AL (Alto), and AL-g2 is AL's second oldest surviving granddaughter. Once a designation, say AL-d2, was made it was retained throughout this report, even though, for example, AL-d1 died during the period. If a female is the only surviving 
daughter or granddaughter of a particular matriarch, no digit is used to refer to her birth order.

\section{RESULTS}

First, we describe briefly the pattern of rank changes during the entire 15 -year period. We then discuss the details of changes that occurred during the 3-year period of this report.

Although predominantly stable rank relations were maintained for more than 11 years (19711982) among the adult females in Alto's Group (see Hausfater et al. 1982 for 1971-1981), a few changes in the relative ranks of single members of matrilines did occur. Four of these changes, involving members of the Fluff, Oval, Preg and Scar matrilines, foreshadowed the subsequent changes described in this report. In addition, Judy dropped to the bottom of the dominance hierarchy in 1973, shortly after the two groups fused. Then, in 1976, OV's rank fell below that of several of the original members of High Tail's Group. Finally, PR and FL-d declined slightly in rank with the rise of SCd2 in 1979. In sum, this was a period of relative stability and slow change in rank relations among matrilines.

Between 1 December 1982 and 1 September 1983, there were substantial changes in the relative rank ordering of matrilines. Although the matrilines involved in these changes were largely the same ones that had experienced rank declines between 1971 and 1981, the frequency and magnitude of rank changes were considerably greater than in previous years. By September 1983, all but the highest ranking matriline had experienced some alteration of their relative rank positions. There were more changes in the relative rank ordering of matrilines during this 9-month period than there had been in the previous 11 years.

From 1 September 1983 until the end of the report period, 1 December 1985 , members of the Fluff, Oval and Preg matrilines continued to decline in rank. During these 27 months, both the frequency and magnitude of changes in dominance rank declined, indicating that a period of slow change and relative stability of rank relations had resumed.

The 10-year period of relative stability in rank relations described by Hausfater et al. (1982) and the substantial changes in rank that followed are

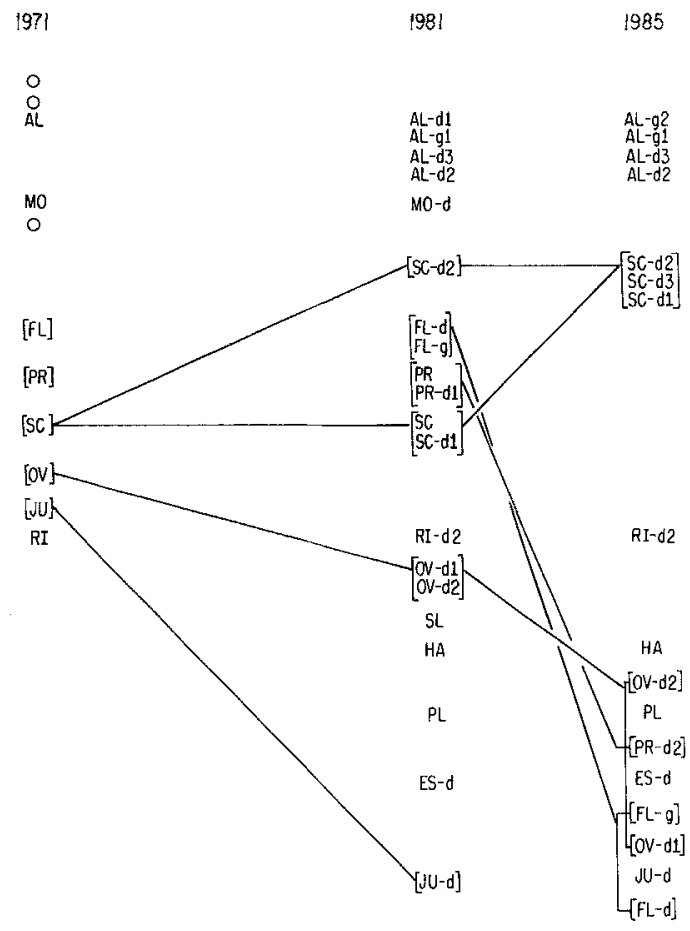

Figure 1. Dominance ranks, 1971, 1981, 1985 (1971 and 1981 based upon Hausfater et al. 1982). Females are listed in descending rank order for each year. Changes in the order of members of families Fluff, Judy, Oval, Preg and Scar are indicated by the use of brackets and lines. All females listed in 1971 were members of the original Alto's Group: open circles denote those that died without leaving female descendants. Female members of the former High Tail's Group at the time of the fusion of the two groups were Este, Slinky, Handle and Plum. ES-d was born after the fusion of the two groups.

summarized in Fig. 1. At the beginning of the report period, 1982, females originating from High Tail's Group (Slinky, Handle, Plum and Este's daughter) were at the bottom of the dominance hierarchy, ranking above only one female from the original Alto's Group, JU-d. Three years later, members of matrilines from the former High Tail's Group (SL, HA, PL and ES-d) ranked above members of four original Alto's Group matrilines (those of Fluff, Judy, Oval and Preg).

\section{Rank Changes Resulting from Agonistic Events}

\section{Period of rapid change}

Our description of changes in dominance rank among adult females focuses upon two brief 
periods, December 1982 to January 1983 and August 1983. It is during these periods that the most substantial changes in the dominance hierarchy occurred. Rank changes occurring during the entire 9 months, December 1982 through August 1983, are summarized in Fig. 2.

In December 1982 and January 1983, two females (FL-g and PR) were defeated by several lower ranking individuals (PR-d1, SC-d1, SC and RI-d2), continuing the declines of members of the Fluff and Preg matrilines. Although there were no reversals in November 1982 ( $N=109$ interactions), a few challenges were observed in December (three reversals out of 181 interactions $=0.0166$ ), and in January there were considerably more reversals ( 15 reversals out of 144 interactions $=0 \cdot 1042$; Table I). The first reversals in rank seen among the females of Alto's Group were against FL-g in midDecember. All but one of the December and January reversals involved FL-g (15 reversals out of 22 interactions) or PR (two reversals out of 12 interactions). Fifteen of the 18 reversals occurred during the turgescent phase of the losers' sexual cycles, a phase that lasts for approximately half of the cycle. Reordering the matrix to minimize the number of reversals indicates that, by the end of January, FL-g fell from rank 7 to rank 11, and PR declined from rank 9 to rank 12 .

These events were accompanied by a series of violent fights between adult females, many of which were directed toward FL-g. A number of these fights involved more than one female simultaneously attacking a single victim, and many involved physical aggression and biting. Polyadic aggression and wounding sometimes occurred when FL-d, the mother of FL-g, retaliated against her daughter's aggressors. Fourteen of the 19 adult females in Alto's Group, including FL-g and PR as well as several females whose ranks did not change, sustained injuries at least once during December and January. The uninjured females were OV-d1, $\mathrm{HA}$ and three of the four members of the topranking Alto matriline.

Some wounds clearly endangered females' lives. One female, ES-d, was bitten on the tail several times. Her wounds became infected, tissue in the lower two-thirds of her tail became necrotic, and eventually this portion of her tail was lost entirely. During this time, ES-d was extremely weak and was unable to maintain contact with the group for at least 1 day. Several other females, whose feet and hands were hurt, limped noticeably.

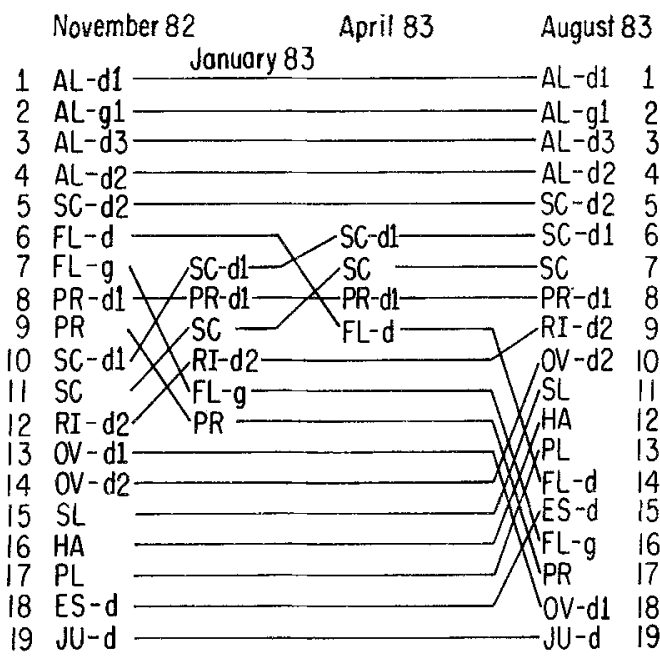

Figure 2. Period of rapid change: December 1982-August 1983. Females are listed in descending rank order. Rank orders of females at the beginning and end of the time period are indicated by the numbers in the first and last columns. Horizontal lines indicate stable rank positions; changes are indicated by the diagonal lines.

There is some indication that fifth-ranking SC$\mathrm{d} 2$ facilitated the rise in rank of her 10th- and 11 thranked mother and sister. In three reversals against FL-g and PR, SC-d2 was observed also to attack her mother's or sister's victim immediately before or after the attack by SC or SC-d1.

During the months of March and April 1983, two additional members of the Fluff and Preg matrilines, PR-d1 and FL-d, were defeated by females SC-d1 and SC. This brought SC and her oldest daughter to rank immediately below $\mathrm{SC}-\mathrm{d} 2$, consolidating the Scar matriline. SC and her daughters were not observed to act together during this period.

The most widespread rank changes occurred in August 1983. The ranks of members of the Fluff, Oval and Preg matrilines dropped precipitously as they were frequently defeated by females who had previously ranked below them. In July, there had been few reversals (six out of $273=0.0220$ ). However, in August, the rate increased tenfold as females frequently defeated individuals who had ranked above them in July ( 84 out of $367=0.2288$. Table II). FL-d, FL-g, PR and OV-d1 were the targets of all of these reversals. By the end of the month, FL-d had fallen from rank 9 to 14, FL-g 


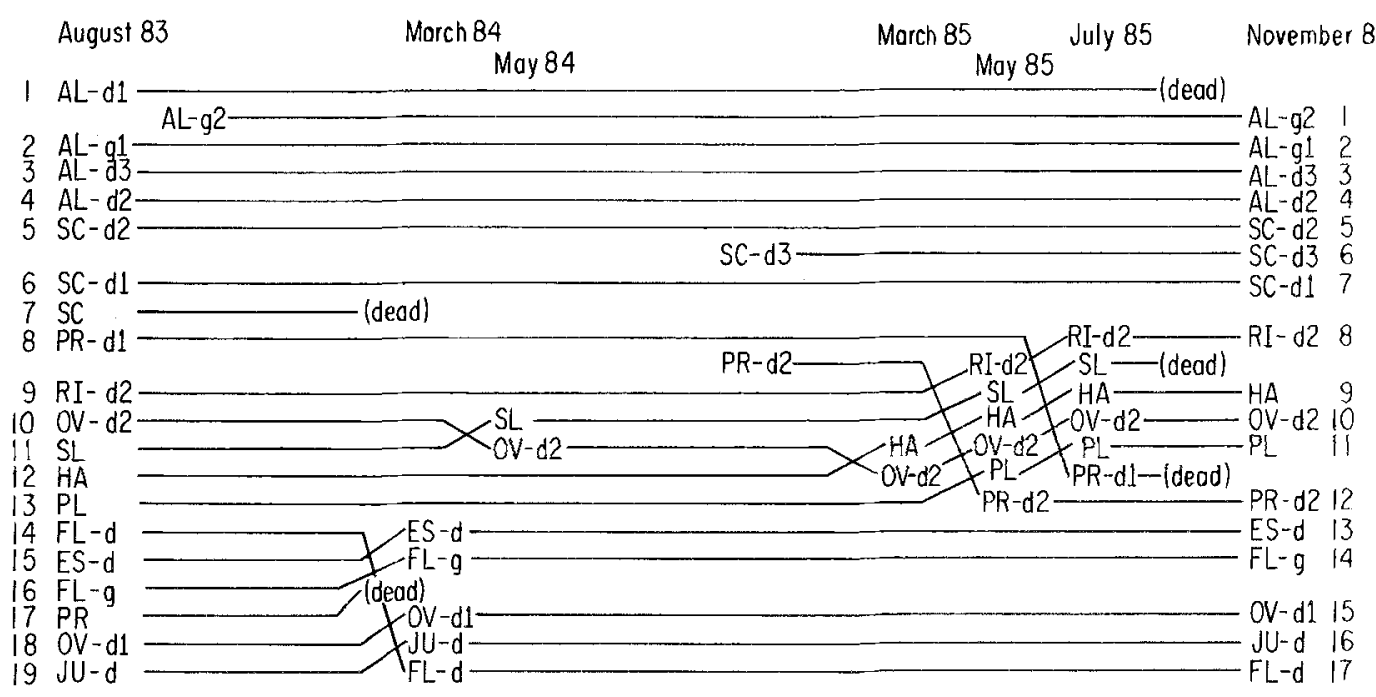

Figure 3. Period of slow change: September 1983-November 1985. Conventions as in Fig. 2. Young females (AL-g2, $\mathrm{SC}-\mathrm{d} 3$ and PR-d2) are added at the time of menarche. A direct comparison of the frequency of rank changes during the time periods depicted in Fig. 2 and Fig. 3 is possible because the two figures are drawn to the same time scale.

had fallen from rank 11 to $16, P R$ had falien from rank 12 to 17 , and OV-d 1 dropped from rank 13 to 18.

The changes that occurred in August 1983 are noteworthy for several reasons. First, these extensive rank changes were accomplished without the violent fights and numerous injuries observed in December and January. Only four of the 19 adult females were wounded in August, and none of these wounds was life-threatening. In addition, there is no evidence to suggest that members of matrilines acted in unison to defeat higher ranking females. Finally, a number of females whose matrilines belonged to Alto's Group before the two groups fused were now dominated by the members of matrilines that formerly belonged to High Tail's Group.

\section{Return to a period of slow change}

During the next 27 months from September 1983 to December 1985, members of the Fluff, Oval and Preg matrilines continued to decline in rank, but rank changes were infrequent and involved only a single female or two sisters (Fig. 3). Dominance relations remained unchanged for 6 months, from September 1983 until March 1984. Then, in March, FL-d dropped below the lowest ranking female in the group, JU-d.
The next rank change occurred when OV-d2 was defeated by the two females ranking immediately below her. SL defeated OV-d2 in May 1984, and HA defeated her 10 months later.

The daughters of PR began to decline in rank in April 1985, 20 months after PR's decline and more than a year after her death. During April and May, PR-d2 was defeated by some but not all of the females who had defeated her mother, RI-d2, SL, HA, OV-d2 and PL. PR-d1 was then defeated by several of those females during the next 2 months. PR-d l's exact position in the dominance hierarchy was not determined because she became seriously ill in June and remained debilitated and peripheral to the group until her death in early September. Before her death, she had been challenged by RI$\mathrm{d} 2$, OV-d2 and PL, but only the defeat by PL had been confirmed by the time of PR-d1's death.

\section{Rank Changes Resulting from Demographic Events}

Five adult females died during the report period. Two old matriarchs, SC and PR, died in February 1984. Three other adult females, AL-d1, PR-d 1 and SL, died in September 1985. These deaths resulted in changes in the absolute, but not relative, rank of all those females that ranked below each of them.

Several changes in absolute rank also occurred 


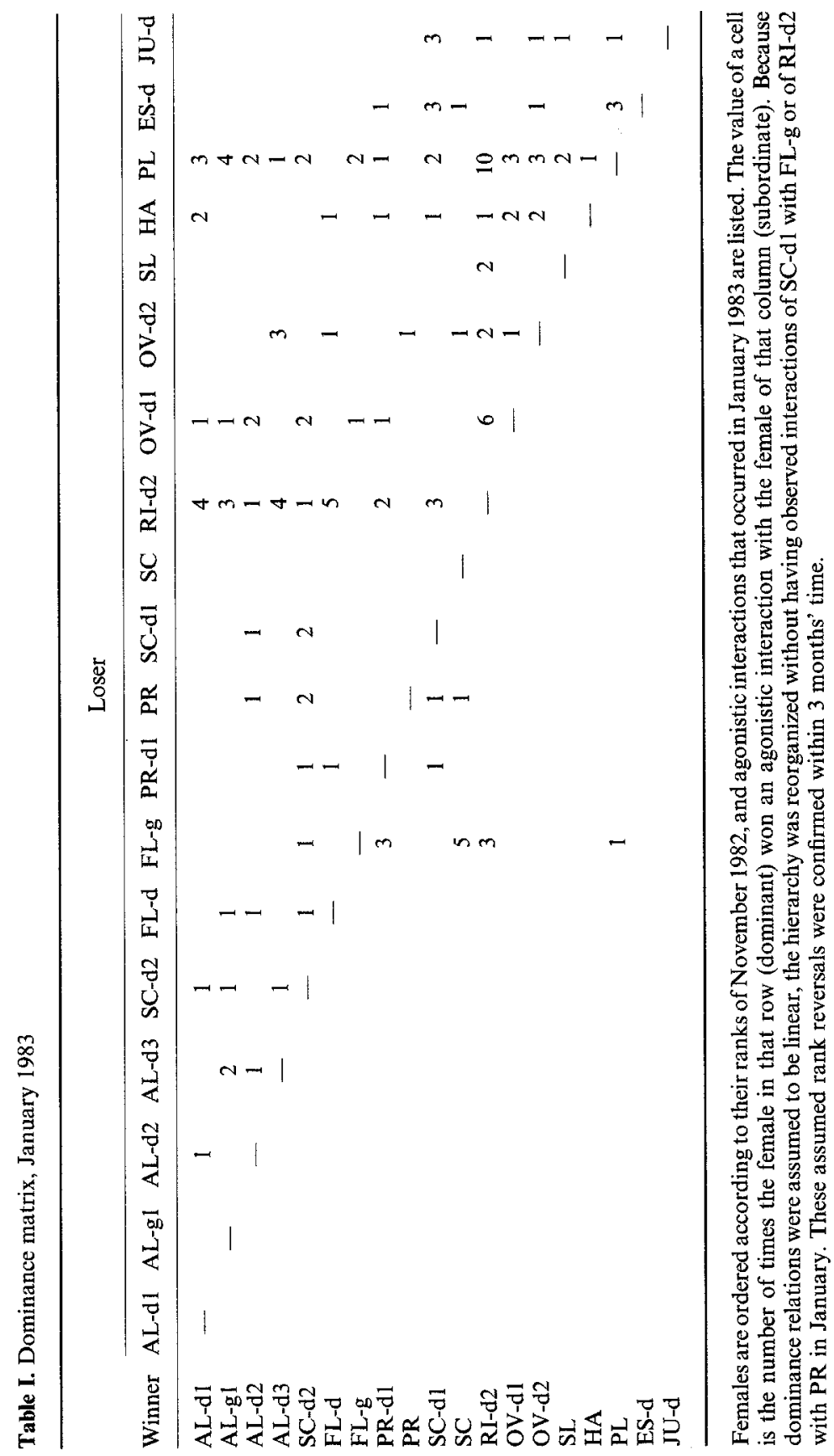




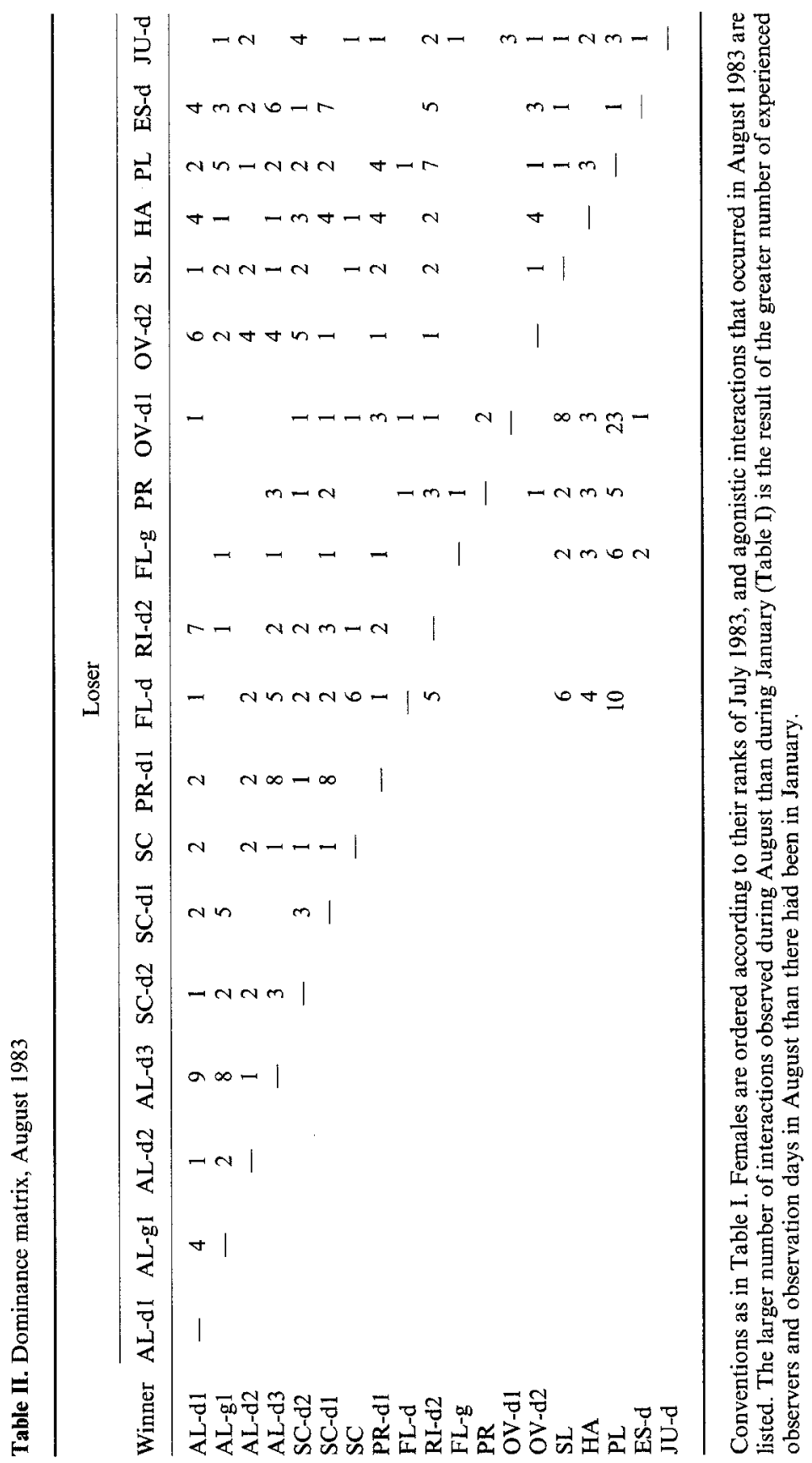


as the result of the maturation of adolescent females. In Amboseli, females typically reach menarche by the time they are 5 years of age (Altmann et al. 1981, in press). By this time, most females have established their positions in the adult female dominance hierarchy (Walters 1980; Hausfater et al. 1982; also see Scott 1984 for P. anubis baboons at Gilgil, Kenya). Three females (AL-g2, PR-d2 and SC-d3) matured during the study period, and each of these females established her 'expected' rank position adjacent to other members of her matriline before the onset of her first menstrual cycle. AL-g2 established her rank position adjacent to members of her matriline prior to November 1982; SC-d3 by February 1984; and PRd2 by December 1984.

\section{DISCUSSION}

It is not clear what caused changes in rank to occur or what caused the rate of these changes to be accelerated. Silk \& Boyd (1983) suggest that changes in dominance rank may be the result of changes in the relative sizes of matrilines. In the present study, this does not explain the declines of the Fluff, Judy and Oval matrilines, which were no smaller than others to which they became subordinate. However, the Scar matriline, which eventually rose to become the second-ranking family, had been second-ranking in size for several years.

Changes in rank sometimes occur following the death, ill health or ageing of a matriarch (Bernstein 1972; Gouzoules 1980; Silk et al. 1981; Hausfater et al. 1982). The decline of PR might have been related to her advancing age; she was over 18 years old and died a year later. However, SC was at least 17 years old when she rose in rank. Although one female, PR-d1, fell in rank after she became ill, her decline in rank was preceded by that of both her mother and sister, and so was unlikely to be a consequence of her illness. None of the other females whose ranks declined during this period was old or ill, and the most recent death among adult females occurred 8 months prior to the initial rank changes in December 1982. With the exception of PR, females whose ranks declined substantially were all 10-12 years of age.

Changes in rank may be more directly related to female reproductive competition in several ways. First, the initial instability in rank relations may be related to the presence of a large number of sexually cycling females (also see Wasser 1983). In December 1982, 12 of the 19 adult females in Alto's Group were sexually cycling, including the four females whose ranks declined during the subsequent months. However, the number of sexually cycling females was not consistently related to the timing of rank changes. Only two females were sexually cycling in August 1983, and the four females who dropped in rank in August were pregnant.

Second, although changes in rank sometimes follow the synchronous maturation of a large number of adolescent females (Samuels \& Henrickson 1983), the number of maturing females is unlikely to have been the catalyst for the events described here. Only three females reached menarche during this period, and they rarely challenged females who were higher ranking than other members of their matrilines. Three other females conceived their first infants during this period. Although two of these females (FL-g and $\mathrm{OV}-\mathrm{d} 2$ ) declined in rank, only FL-g was a target of aggression during the months preceding the conception of her first infant in March 1983.

The reproductive maturation of this late-adolescent female, FL-g, may have triggered the aggression towards her, resulting in the first observed reversals and in violent fights and wounding. Aggression towards FL-g occurred primarily during the turgescent phase of her sexual cycles and occurred during the first months that mature males were sexually interested in her.

A long period of stability in dominance relations among female baboons in Amboseli was punctuated by a short period of instability and change, followed by another period of stability which lasted to the end of the report period. Although when the report period ended, the Oval and Fluff matrilines were divided and PR-d2 was higher ranking than PR had been at the time of her death, we note that the ending time of this report is arbitrary. Continued declines in rank of members of the Fluff, Oval and Preg families during 1985 suggest that in time these matrilines may be consolidated in the hierarchy. Additional years of research in Amboseli and on cercopithecines elsewhere will be needed to determine whether the phenomenon we observed is a recurrent pattern, and to estimate reliably the rate of changes in rank. Although rapid changes in rank have been a focus of the present report, it is important to bear in mind the considerable continuity and stability of female dominance relations, 
and to recall that this stability is much greater than that among males of the same species (Hausfater 1975).

\section{ACKNOWLEDGMENTS}

We are appreciative of the hospitality and cooperation provided by the Office of the President, the National Council of Science and Technology, the Zoology Department of the University of Nairobi and the National Parks, all in Kenya. To M. Buteyo, J. Else, G. Lolkinyei, B. Oguya and D. Sindiyo we are particularly grateful. We thank Amboseli fieldworkers, S. C. Alberts, B. J. King, R. S. Mututua, B. Noe and R. Noe for their contributions to observations in this report. We also thank V. S. Sikawa for her assistance with data tabulation; M. Altmann and S. Galhotra for their assistance with computer programming; and $\mathrm{C}$. Johnson for her assistance in the preparation of tables and figures. We thank S. Altmann, C. Berman, G. Hausfater, P. Lee, S. Smith, B. Smuts, J. Walters and an anonymous reviewer for commenting upon previous drafts. Financial support has been provided by the H. F. Guggenheim Foundation, the U.S. Public Health Service (HD15007) and the National Science Foundation (BSR-8219127).

\section{REFERENCES}

Altmann, J. 1980. Baboon Mothers and Infants. Cambridge, Massachusetts: Harvard University Press.

Altmann, J., Altmann, S. \& Hausfater, G. 1981. Physical maturation and age estimates of yellow baboons, Papio cynocephalus. Am. J. Primatol., 1, 389-399.

Altmann, J., Hausfater, G. \& Altmann, S. In press. Determinants of reproductive success in savannah baboons (Papio cynocephalus). In: Reproductive Success (Ed. by T. H. Clutton-Brock). Chicago: University of Chicago Press.

Altmann, J., Altmann, S., Hausfater, G. \& McCuskey, S. 1977. Life history of yellow baboons: physical development, reproductive parameters, and infant mortality. Primates, 18, 315-330.

Altmann, S. \& Altmann, J. 1970. Baboon Ecology: African Field Research. Basel: S. Karger and Chicago: University of Chicago Press.

Angst, W. 1975. Basic data and concepts on the social organization of Macaca fascicularis. In: Primate Behavior, Developments in Field and Laboratory Research. Vol. 4 (Ed. by L.A. Rosenblum), pp. 325-388. New York: Academic Press.

Bernstein, I.S. 1969. The stability of the status hierarchy in a pigtail monkey group (Macaca nemestrina). Anim. Behav., 17, 452-458.
Bernstein, I.S. 1972. Daily activity cycles and weather influences on a pig-tail monkey group. Folia primatol., 18, 390-415.

Cheney, D.L., Lee, P.C. \& Seyfarth, R.M. 1981. Behavioral correlates of non-random mortality among freeranging female vervet monkeys. Behav. Ecol. Sociobiol., 9, 153-161.

Estrada, A. 1978. Social relations in a free ranging group of Macaca arctoides. In: Recent Advances in Primatology. Behaviour. Vol. 1 (Ed. by D. J. Chivers \& J. Herbert), pp. 55-58. New York: Academic Press.

Fedigan, L.M. 1983. Dominance rank and reproductive success in primates. Ybk phys. Anthropol., 26, 91-129.

Gouzoules, H. 1980. A description of genealogical rank changes in a troop of Japanese monkeys (Macaca fuscata). Primates, 21, 262--267.

Gouzoules, H., Gouzoules, S. \& Fedigan, L. 1982. Behavioural dominance and reproductive success in female Japanese monkeys (Macaca fuscata). Anim. Behav., 30, 1138-1150.

Hausfater, G. 1975. Dominance and reproduction in baboons (Papio cynocephalus): a quantitative analysis. Contrib. Primatol., 7, 1-150.

Hausfater, G., Altmann, J. \& Altmann, S. 1982. Longterm consistency of dominance relations among female baboons (Papio cynocephalus). Science, N.Y., 217, 752-. 755.

Koyama, N. 1967. On dominance rank and kinship of a wild Japanese monkey troop in Arashiyama. Primates, 8, $189-216$.

Sade, D.S. 1972. A longitudinal study of social behavior of rhesus monkeys. In: The Functional and Evolutionary Biology of Primates (Ed. by R. Tuttle), pp. 378-398. Chicago: Aldine.

Samuels, A. \& Henrickson, R.V. 1983. Outbreak of severe aggression in captive Macaca mulatta. Am. J. Primatol., 5, 277-281.

Scott, L.M. 1984. Reproductive behavior of adolescent female baboons (Papio anubis) in Kenya. In: Female Primates: Studies by Women Primatologists (Ed. by M. F. Small), pp. 77-100. New York: Alan R. Liss.

Silk, J.B. 1987. Social behaviour in evolutionary perspective. In: Primate Societies (Ed. by B. Smuts, D.L. Cheney, R.M. Seyfarth, R.W. Wrangham \& T.T. Struhsaker, pp. 318-329. Chicago: University of Chicago Press.

Silk, J.B. \& Boyd, R. 1983. Cooperation, competition, and mate choice in matrilineal macaque groups. In: Social Behavior of Female Vertebrates (Ed. by S.K. Wasser), pp. 316-348. New York: Academic Press.

Silk, J.B., Samuels, A. \& Rodman, P.S. 1981. Hierarchical organization of female Macaca radiata. Primates, 22, $84-95$.

Walters, J. 1980. Interventions and the development of dominance relationships in female baboons. Folia primatol., 34, 61-89.

Wasser, S.K. 1983. Reproductive competition and cooperation among female yellow baboons. In: Social Behavior of Female Vertebrates (Ed. by S.K. Wasser), pp. 349-390. New York: Academic Press.

(Received 26 February 1986; revised 16 May 1986; MS. number: $A 4727$ ) 